\title{
Mental health, job satisfaction, and job stress among general practitioners
}

\author{
Cary L Cooper, Usha Rout, Brian Faragher
}

\begin{abstract}
Objective-To identify sources of job stress associated with high levels of job dissatisfaction and negative mental wellbeing among general practitioners in England.

Design-Multivariate analysis of large database of general practitioners compiled from results of confidential questionnaire survey. Data obtained on independent variables of job stress, demographic factors, and personality. Dependent variables were mental health, job satisfaction, alcohol consumption, and smoking.
\end{abstract}

Setting-National sample of general practitioners studied by university department of organisational psychology.

Subjects-One thousand eight hundred seventeen general practitioners selected at random by 20 family practitioner committees in England.

Interventions-None.

End point-Determination of the combination of independent variables that were predictive of mental health and job satisfaction.

Measurements and main results - Women general practitioners both had job satisfaction and showed positive signs of mental wellbeing in contrast with other normative groups. Conversely, male doctors showed significantly higher anxiety scores than the norms, had less job satisfaction, and drank more alcohol than their women counterparts. Multivariate analysis disclosed four job stressors that were predictive of high levels of job dissatisfaction and lack of mental wellbeing; these were demands of the job and patients' expectations, interference with family life, practice administration.

Conclusions - There may be substantial benefit in providing a counselling service for general practitioners and other health care workers who suffer psychological pressure from their work.

University of Manchester Institute of Science and Technology, PO Box 88, Manchester M60 1QD

Cary L Cooper, PHD professor of organisational psychology

Usha Rout, Msc, research fellow in organisational psychology

Brian Faragher, Msc, medical statistician (Withington

Hospital)

\section{Correspondence to:}

Professor Cooper,

department of organisational psychology.

Br.Med f 1989;298:366-70

Murray found that the rate of first admissions for alcohol dependence was two to seven times higher among doctors than among controls of comparable social class. ${ }^{3}$ In the United States 13 000-22 000 doctors were alcohol dependent at some stage in their career. ${ }^{+}$ The General Medical Council reported that of 51 general practitioners investigated between September 1980 and August 1981, 19 were classified as drug constant interruptions at work and home, and

addicts or alcoholics. Allibone et al estimated that there may be as many as 3000 practising general practitioners who are alcoholics and that many others may show other signs of stress. ${ }^{5}$ The Registrar General's mortality figures showed that medical practitioners have a higher risk of dying from three causes frequently linked to stress-namely, suicide (standardised mortality ratio 335), cirrhosis (standardised mortality ratio 311), accidental poisoning (standardised mortality ratio 818), and accidents (standardised mortality ratio 180). ${ }^{\circ}$ Rose and Roscow reviewed death certificates in California from 1959 to 1961 and found that general practitioners were twice as suicide prone as the general population. In addition, the incidence of and mortality from myocardial infarcts was about twice as high in general practitioners (aged 40-60) as in other members of the profession of comparable age. ${ }^{8}$

These mortality and morbidity statistics show that general practitioners may indeed be at considerable risk of illnesses and other manifestations related to stress. Though much has been written about the possible causes of this stress-for example, heavy workload, dealing with the terminally ill, excessive paperwork, and so on-little large scale empirical work is available. Our investigation was aimed at highlighting the sources of stress in general practitioners that are predictive of high levels of negative mental wellbeing and job dissatisfaction.

The investigation was done in three parts. Firstly, an in depth interview was carried out on a pilot sample of general practitioners $(n=42)$. Secondly, a job stress inventory for general practitioners was formulated on the basis of these interviews. This inventory, together with other measures, was then piloted on a sample of over 100 general practitioners in the north west of England. Thirdly, a finalised set of instruments was prepared for distribution to a national sample of general practitioners. This battery of tests included two dependent variables-namely, a mental health measure (Crown-Crisp experiential index ${ }^{9}$ ) and a job satisfaction measure (Warr-Cook-Wall job satisfaction scale $\left.^{10}\right)$ - and three independent variables - namely, a set of personal and job demographic items, a personality measure (Bortner type A questionnaire ${ }^{11}$ ), and the general practitioner job stress inventory. Two items on smoking and drinking were also included. The ultimate purpose of the study was to assess which combination of independent variables - that is, personal and job demographic factors, type A behaviour, and job stressors - was predictive of each of the two dependent variables - that is, mental health and job satisfaction.

\section{Methods}

SAMPLE

The package of questionnaires was sent to a random sample of 4000 general practitioners through- 
out England. They were distributed by 20 family practitioner committees, selected to reflect a representative sample of practices in terms of urban versus rural, social mix of area, and other demographic characteristics. A total of 1928 questionnaires were returned (response rate $48 \cdot 2 \%$ ), of which 1817 were complete for statistical analysis (those excluded had substantial incomplete sections or arrived beyond the cut off date for analysis). Absolute confidentiality was ensured by general practitioners returning their questionnaires to the University of Manchester Institute of Science and Technology anonymously. This meant, however, that we were unable to check any differences between responders and non-responders and were unable to assess test-retest reliability of the job stress questionnaire. Anonymity, however, was considered essential to protect the identity of the doctors, to ensure honesty in responding, and to obtain a reasonable response rate. The response rate was above average as compared with similar occupational stress studies. ${ }^{12}$

The sample comprised $1474(81 \cdot 1 \%)$ male doctors and $343(18.9 \%)$ women doctors; $509(28.0 \%)$ were aged $25-34,638(35 \cdot 1 \%) 35-44,367(20 \cdot 2 \%) 45-54,276$ $(15 \cdot 2 \%) 55-64$, and $27(1.5 \%) 65$ or over. A total of $1539(84.7 \%)$ of the doctors were married, 1657 $(91 \cdot 2 \%)$ were in group practices, $1753(96.5 \%)$ were principals, and $204(11 \cdot 2 \%)$ had received their first degree overseas. The demographic picture of the sample was typical of general practitioners nationally with respect to all characteristics, except that slightly fewer doctors aged 65 or over responded."

\section{MEASURING INSTRUMENTS}

\section{Dependent variables}

Data were collected from each general practitioner on his or her degree of job satisfaction and mental health. Data were also collected on smoking and alcohol consumption.

Fob satisfaction-The Warr-Cook-Wall job satisfaction scale was developed with a British population and has been used extensively among differing occupational groups in Britain. Test-retest reliability and validity data have been reported. ${ }^{10}$ The scale provides a short, reliable, valid, and easy to use measure of job satisfaction. The 15 items, with seven point Likert type rating scales for each item, assess the degree of job satisfaction ranging from "extremely dissatisfied" (score 1) to "extremely satisfied" (score 7). Only 10 items were used in this investigation, the other five not being appropriate for general practitioners (for example, "your immediate boss," "your job security") The items used were "physical working conditions," "freedom to choose your own method of working," "your colleagues and fellow workers," "recognition you get for your good work," "amount of responsibility you are given," "your rate of pay," "opportunity to use your ability," "your hours of work," "amount of variety in your job," and "taking everything into consideration, how do you feel about your job as a whole?"

Mental health-Psychological wellbeing and mental health were measured by a shortened version of the Crown-Crisp experiential index (formerly known as The Middlesex Hospital questionnaire). ${ }^{9}$ Only the three most reliable and appropriate subscales of the index were used-namely, free floating anxiety, depression, and somatic anxiety. Each of these subscales is composed of eight items (scored 0,1 , or 2 ), so giving a total of 24 and providing an overall index of mental health. A low score was indicative of good mental health. Reliability and validity data have been reported. ${ }^{14}$

Health behaviours-Two items measuring alcohol consumption and cigarette smoking were also included as dependent variables in the questionnaire. For each a six point Likert type item assessing the degree of daily consumption was included. Zero consumption scored as 0 on both scales. Regularly taking more than six drinks a day scored 5 , as did a daily cigarette consumption of 40 or more.

\section{Independent variables}

Data for each general practitioner on his or her personal and job demographic factors, type A behaviour, and sources of job stress served as the independent variables.

Personal and job demographic factors-Data were obtained on nine demographic characteristicsnamely, age, sex, marital state, principal versus trainee, practice type (single handed versus group), qualified in the United Kingdom versus overseas, postgraduate qualifications, year spent in general practice, and location of practice (urban versus rural).

Type A behaviour-A slightly adapted version of the Bortner type A questionnaire was used as an indicator of stress prone personality. ${ }^{.1}$ In recent years the type A pattern of behaviour has emerged as a good predictor of cardiovascular disease and other stress related illness. Type A behaviour may be characterised by extremes of competitiveness, striving for achievement, aggressiveness, haste, impatience, restlessness, hyperalertness, explosiveness of speech, tenseness of facial muscles, and feelings of being under pressure of time and under the challenge of responsibility. The Bortner type A questionnaire consists of 14 bipolar adjectival scales with 11 point Likert type rating continua scored from 1 to 11. The items assess different aspects of this behaviour pattern and are: never late $v$ casual about appointments; not competitive $v$ competitive; anticipates what others are going to say $v$ good listener; always rushed $v$ never feels rushed; can wait patiently $v$ impatient while waiting; goes all out $v$ casual; takes things one at a time $v$ tries to do many things at once;

TABLE I-Factor analysis of job stressors for general practitioner

Stressors Loadings

Factor 1 . Demands of job and patients' expectations

( $62 \cdot 8 \%$ of variance):

Fear of assault during night visits

Visiting in extremely adverse weather conditions

Adverse publicity by media

Increased demand by patients and relatives for second opinion from hospital specialists

No appreciation of your work by patients

Worrying about patients' complaints

Finding a locum

Twenty four hour

(I)

Taking several samples in a short time

Unrealistically high expectations by others of your role

Factor 2. Interruptions (10.6\% of variance):

Coping with phone calls during night and early morning

Night calls

Interruption of family life by telephone

Emergency calls during surgery hours

Home visits

Dealing with problem patients

Remaining alert when on call

Factor 3. Practice administration ( $8.6 \%$ of variance):

Hospital referrals and paperwork

Conducting surgery

Practice administration

Arranging admissions

Working environment (surgery set up)

Time pressure

Factor 4 . Work:home interface and social life

(7.7\% of variance :

Demands of your job on family life

Dividing time between spouse and patients

Demands of your job on social life

Lack of emotional support at home, especially from spouse Interruption of family life by telephone

Factor 5. Dealing with death and dying (5.5\% of variance): Daily contact with dying and chronically ill patients Dealing with the terminally ill and their relatives

Factor 6. Medical responsibility for friends and relatives ( $4.8 \%$ of variance)

Dealing with friends as patients

Dealing with relatives as patients 
emphatic in speech $v$ slow, deliberate talker; wants good job recognised by others $v$ cares about satisfying himself or herself no matter what others think; fast $v$ slow (at eating, walking, and so on); easy going $v$ hard driving; hides feelings $v$ expresses feelings; many outside interests $v$ few outside interests; and unambitious $v$ ambitious. An overall type A measure was obtained by summing the scores on the individual items, high scores indicating greater manifestations of type A. Reliability and validity data have been described."

fob stressor questionnaire - The job stress inventory for general practitioners was developed on the basis of in depth interviews with 42 general practitioners and a pilot survey of over 100 general practitioners in the north west of England. ${ }^{15}$ The final questionnaire consisted of 38 items accompanied by a five point Likert type rating scale ranging from no stress at all (rating 1) to a source of extreme stress (rating 5). The 38 items were then factor analysed to assess which items were intercorrelated and to establish their internal reliability. Table I lists the 33 items grouped statistically into six factors - namely, demands of the job and patients' expectations; interruptions; practice administration; work:home interface and social life; dealing with death and dying; and medical responsibility for friends and relatives. A principal factor analysis (with iteration) was performed to identify groups of variables which accounted for the observed correlations in the data set. A varimax rotation was also applied to ensure that so far as possible each variable appeared in only one factor grouping. ${ }^{16}$ Factor scores were calculated for each general practitioner for each factor and were ultimately used in the multiple regression analyses.

\section{STATISTICS}

To analyse the relation between the dependent variables (job satisfaction, mental health measures) and independent variables (personal and job demographic factors, type A behaviour, job stressors) stepwise multiple regression analysis was used. Most of the scales utilised five point Likert type rating responses. Given the large sample size, the distribution of these scales was found to approximate closely to normality. Multiple regression relates independent and dependent variables in a manner which takes mathematical intercorrelation into account. This statistical technique achieves the best linear prediction equation between an independent variable (in this case demographic factors, type A, or job stressors) and a series of dependent variables (in this case overall job satisfaction and the overall mental health index) Interaction between the dependent variables was not considered. In trying to isolate the job stressors, type $A$, and demographic variables that would yield the optimal prediction equation the cut off point was determined by two statistical criteria - namely, $(a)$ that the overall $\mathrm{F}$ ratio for the equation was significant and (b) that the partial regression coefficient for the individual independent variable being added was at a statistically significant level or one approaching significance. ${ }^{17}$ Below this point not only is the coefficient insignificant but also the amount of the variance contributed by each additional variable ( $R^{2}$ change) is very small.

In addition to multivariate analyses identifying the independent variables most predictive of lack of mental wellbeing and job dissatisfaction, unpaired Student's $t$ tests and one way analyses of variance were used to compare sample subgroups for each variable separately. The Bonferroni test of inequality was employed to minimise the risk of type I errors. Statistical significance was set at the conventional $5 \%$ level throughout.
Results

JOB SATISFACTION

Before carrying out multivariate analyses of the data we assessed general practitioners' job satisfaction scores. Table II shows the means and standard deviations for each of the job satisfaction scales. The highest levels of satisfaction were reported for the amount of responsibility given, amount of freedom in choosing working methods, and amount of variety in the job.

TABLE II - Fob satisfaction (in order of importance) $(n=1817)$

\begin{tabular}{lcc}
\hline Dimensions $^{\star}$ & Mean & SD \\
\hline Amount of responsibility you are given & $5 \cdot 68$ & $1 \cdot 09$ \\
Freedom to choose your own method of. working & $5 \cdot 40$ & $1 \cdot 26$ \\
Amount of variety in your job & $5 \cdot 38$ & $1 \cdot 20$ \\
Your fellow workers & $5 \cdot 24$ & $1 \cdot 25$ \\
Physical working conditions & $5 \cdot 11$ & 1.41 \\
Opportunity to use your ability & $5 \cdot 04$ & $1 \cdot 35$ \\
Your rate of pay & $4 \cdot 77$ & 1.56 \\
Recognition you get for your good work & $4 \cdot 76$ & $1 \cdot 18$ \\
Your hours of work & $4 \cdot 25$ & 1.57 \\
Overall job satisfaction & $5 \cdot 23$ & $1 \cdot 15$
\end{tabular}

$\star$ Each dimension scored 1-7; the higher the score the higher the satisfaction.

This supports the findings of Cartwright and Anderson that general practitioners enjoy the diversity of their work and appreciate their freedom and independence. ${ }^{18}$ On the basis of factor analysis Warr et al suggested that four dimensions of job satisfaction (freedom, responsibility, variety, ability) constitute "intrinsic" job satisfaction. ${ }^{10}$ Table II shows that three of these had the highest ratings. The lowest levels of satisfaction derived from "extrinsic" job factors mentioned by Warr et al-namely, hours of work and rate of pay. We also found that women general practitioners (mean 52.8 (SD 7.36)) were significantly more satisfied with their job $(p<0.001)$ than male general practitioners (mean $50.3(8.23)$ ) and that general practitioners who had qualified in the United Kingdom (mean 51.5 (SD 7.65)) were significantly more satisfied $(p=0.003)$ than those who had qualified overseas (mean 49.1 (11.07)). There was no significant difference between general practitioners who were in single handed as compared with group practices, and no difference between trainees and principals in terms of job satisfaction.

Stepwise multiple regression analysis was calculated with job satisfaction as the dependent variable against demographic factors, type $\mathrm{A}$, and job stressors as the independent variables. Table III shows that four of the job stressors were negatively predictive of high levels of job satisfaction among general practitioners; they were the demands of the job and patients' expectations, work:home interface and social life, interruptions, and practice administration. In addition, male general practitioners entered into the equation as significantly more dissatisfied with their job. These factors accounted for $20 \%$ of the variance. When we broke the data down for men and women and carried out stepwise multiple regression analysis on each of these groups separately the same four factors emerged in both equations. Interestingly, however, for male general practitioners the most significant predictor was

TABLE III-Multiple regression analysis of demographic factors, type $A$ behaviour, and job stressors against job satisfaction

\begin{tabular}{lllll}
\hline Step & Independent variables & $\begin{array}{c}\text { Beta } \\
\text { coefficient }\end{array}$ & $\mathrm{SE}$ & $\mathrm{R}^{2}$ \\
\hline 1 & Demands of job and patients & & & \\
& $\quad$ expectations & -2.48 & $0 \cdot 23$ & $0 \cdot 07$ \\
2 & Work:home interface and social life & -1.53 & $0 \cdot 22$ & $0 \cdot 12$ \\
3 & Interruptions & -1.62 & $0 \cdot 23$ & $0 \cdot 15$ \\
4 & Practice administration & -1.56 & 0.23 & $0 \cdot 18$ \\
5 & Woman general practitioner & $3 \cdot 01$ & $0 \cdot 55$ & $0 \cdot 20$ \\
\hline Overall $\mathrm{F}=69 \cdot 67, \mathrm{df}=5,1407, \mathrm{p}<0 \cdot 001$. & & &
\end{tabular}

Overall $\mathrm{F}=69 \cdot 67, \mathrm{df}=5,1407, \mathrm{p}<0 \cdot 001$ 
demands of the job and patients' expectations; whereas for women it was the work:home interface and socia life. Overall the demands of the job and patients' expectations as well as the impact of the job on family and social life were the two most significant job stressors.

\section{MENTAL HEALTH}

The three subscales of the Crown-Crisp experiential index for general practitioners were compared with the national normative data. Table IV shows that women general practitioners had significantly lower scores on free floating anxiety, depression, and somatic anxiety than a British normative sample of women. Male

TABLE IV-Differences between general practitioners and normative population on free floating anxiety, somatic anxiety, and depression scales of Crown-Crisp experiential index

\begin{tabular}{|c|c|c|c|c|c|}
\hline \multirow[b]{2}{*}{ Factor } & \multicolumn{2}{|c|}{ General practitioners } & \multicolumn{2}{|c|}{ Population } & \multirow[b]{2}{*}{$\mathrm{p}$} \\
\hline & Mean & SE & Mean & SE & \\
\hline \multicolumn{6}{|c|}{ Free floating anxiety: } \\
\hline Women & $4 \cdot 48$ & $0 \cdot 18$ & $5 \cdot 40$ & $0 \cdot 17$ & $<0.05$ \\
\hline Men & $3 \cdot 70$ & $0 \cdot 08$ & $2 \cdot 80$ & $0 \cdot 15$ & $<0 \cdot 01$ \\
\hline \multicolumn{6}{|c|}{ Somatic anxiety: } \\
\hline Women & 2.65 & $0 \cdot 12$ & $5 \cdot 70$ & $0 \cdot 16$ & $<0.01$ \\
\hline Men & $2 \cdot 36$ & $0 \cdot 06$ & $4 \cdot 30$ & $0 \cdot 16$ & $<0.01$ \\
\hline \multicolumn{6}{|l|}{ Depression: } \\
\hline Women & $3 \cdot 37$ & $0 \cdot 13$ & $4 \cdot 40$ & $0 \cdot 12$ & $<0.01$ \\
\hline Men & $2 \cdot 94$ & 0.07 & $3 \cdot 20$ & $0 \cdot 12$ & NS \\
\hline
\end{tabular}

Male $(n=340)$ and female $(n=415)$ normative data for Crown-Crisp experiential index obtained by Crown and Crisp ${ }^{1+}$ on random sample of patients in two large group general practices, one in urban and the other in rural area. In present series complete data in respect of Crown-Crisp experiential data obtained for 1439 male general practitioners and 335 women general practitioners.

general practitioners, on the other hand, had a significantly higher score on free floating anxiety than a British normative male population. They showed no significant difference compared with male norms on depression but had significantly lower scores on the somatic anxiety scale. Women general practitioners therefore appeared to have significantly increased levels of mental wellbeing, whereas male general practitioners were more emotionally anxious but did not reflect this in psychosomatic complaints. Both male general practitioners and women doctors had substantially different scores on all three mental health subscales compared with a national sample of general dental practitioners. ${ }^{19}$

Stepwise multiple regression analysis of demographic factors, type A behaviour, and job stressors was carried out against the overall mental health index (summation of the three subscales) for the whole sample of general practitioners and then for men and women separately. Four job stressors and age, sex, and type A behaviour were significantly predictive of high levels of mental ill health or lack of wellbeing. Table $\mathrm{V}$ shows that interruptions at work and home-for example, night calls, interruption of family life by telephone, emergency calls during surgery - the stress of practice administration - for example, managing the practice, hospital referral, paperwork-demands of

TABLE $\mathrm{V}-$ Multiple regression analysis of demographic factors, type A behaviour, and job stressors against mental health index for general practitioners

\begin{tabular}{llccc}
\hline Step & $\quad$ Independent variables & $\begin{array}{c}\text { Beta } \\
\text { coefficient }\end{array}$ & SE & R \\
\hline 1 & Interruptions & $1 \cdot 48$ & $0 \cdot 19$ & $0 \cdot 05$ \\
2 & Practice administration & $1 \cdot 60$ & $0 \cdot 19$ & $0 \cdot 09$ \\
3 & Demands of job and patients & & & \\
& $\begin{array}{l}\text { expectations } \\
4\end{array}$ Work:home interface and social life & $1 \cdot 15$ & $0 \cdot 19$ & $0 \cdot 12$ \\
5 & Age group & $1 \cdot 15$ & $0 \cdot 18$ & $0 \cdot 15$ \\
6 & Sex (female) & $2 \cdot 22$ & $0 \cdot 16$ & $0 \cdot 18$ \\
7 & Type A & $0 \cdot 04$ & $0 \cdot 01$ & $0 \cdot 19$ \\
& & & & \\
\hline
\end{tabular}

Overall $\mathrm{F}=48 \cdot 23, \mathrm{df}=7,1362, \mathrm{p}<0 \cdot 001$. the job and patients' expectations-for example, no appreciation of general practitioners' work, worrying about patients' complaints, unrealistic expectations of the general practitioner's role-and impact of the work:home interface-for example, dividing time between spouse and patients, demands of job on family life-together contributed over $15 \%$ of the variance and accounted for roughly equivalent amounts of variance in predicting lack of mental wellbeing among general practitioners. Given the demographic and type A behaviour variables in the equation, evidently the general practitioners most at risk of the four job stress factors were those who were older, were male, and who reflected a type A pattern of behaviour in their lifestyle - for example, who were hard driven, overly conscious of time, assertive, ambitious, and so on.

When we broke the analysis down by men and women the separate regressions yielded the same four job stressors as significant predictors of high levels of negative mental wellbeing for both sexes. Interestingly, however, the most significant predictor for women general practitioners (accounting for $8 \%$ of variance alone out of a total $\mathrm{R}^{2}$ of $21 \%$ ) was the stress of the job interfering with family life, whereas demands of the job, and patients' expectations and practice administration were less important. For male general practitioners, on the other hand, the work:home interface was the least important predictor, interruptions, practice administration, and demands of the job and patients' expectations being the more significant variables in the equation.

\section{HEALTH BEHAVIOURS}

A total of $1661(91.4 \%)$ of the general practitioners did not smoke cigarettes, only $29(1 \cdot 6 \%)$ smoking over 20 cigarettes a day. As far as self reported alcohol consumption was concerned, $116(6 \cdot 4 \%)$ general practitioners were teetotal, $590(32.5 \%)$ had an occasional drink, $667(36.7 \%)$ had several drinks a week, 338 $(18.6 \%)$ had one or two drinks every day, $98(5.4 \%)$ had three to six drinks daily, and $7(0.4 \%)$ had more than six drinks daily. Owing to the possible bias of social desirability effect these self reports of alcohol consumption are likely to be underrepresented.

There were no significant differences in smoking behaviour between men and women general practitioners, but men apparently consumed significantly more alcohol $(p=0.002)$. Though there were no significant differences between general practitioners in group compared with solo practices with respect to cigarette consumption, those in group practices consumed significantly more alcohol $(\mathrm{p}<0 \cdot 001)$. General practitioners trained in the United Kingdom consumed significantly more alcohol than those trained overseas, but there were no differences in smoking behaviour. Finally, there were no differences between principals and trainees in terms of either drinking or smoking behaviour.

As there was a comparatively normal distribution of responses in respect of drinking behaviour (but not for smoking, given the high number of non-smokers), we decided to carry out stepwise multiple regression of our independent variables - that is, demographic factors, type A, and job stressors-against degree of drinking behaviour, and by men and women general practitioners separately. As the total amount of variance $\left(\mathbf{R}^{2}\right)$ for each of these equations was very small (between $4 \%$ and $9 \%$ ), no conclusions could be drawn. Interestingly, however, one of the job stressors that had not previously appeared in the job satisfaction and mental health regression equations - namely, dealing with death and dying-was prevalent in the drinking behaviour analyses. This was particularly so in respect of women general practitioners. 


\section{Discussion}

In general, the general practitioner's job is a source of considerable job satisfaction. General practitioners have high levels of "intrinsic" job satisfaction as a result of the autonomy and freedom of their working methods. On balance, the mental health of general practitioners is quite good in contrast with the normative population. Women general practitioners indicated remarkable mental wellbeing, mental health scores being significantly below the normative population norms on measures of anxiety, depression, and somatic anxiety. For male general practitioners the results were more mixed, with significantly higher anxiety scores than the male normative population. In addition, male general practitioners showed significantly less job satisfaction and more alcohol consumption than their women colleagues.

By far the most important aspect of the study was in highlighting the sources of job stress among general practitioners. We found that they could be broken down into six different factors. The multiple regression analyses were interesting in that the same four job stressor factors were predictive of high levels of job dissatisfaction and lack of mental wellbeing. The demands of the job and patients' expectations of the general practitioner, the job interfering with family life, constant interruptions at home and work, and the stresses of practice administration-for example, hospital referrals and paperwork-emerged as the main barriers to greater job satisfaction and mental health. Interestingly, male general practitioners were affected more by the work related aspects of the job (practice administration, job demands), whereas women general practitioners were affected more by the job interfering with their family life. This may reflect the fact that women general practitioners are more likely to work part time than their male colleagues. In addition, general practitioners most at risk of the job adversely affecting their mental health were male, older, and tended to exhibit a type A pattern of behaviour. Though the factors identified clearly related to job stress, only $20 \%$ of the variation was accounted for by these factors. This indicated that there are other factors related to job satisfaction and mental health of general practitioners that should be studied-for example, coping styles.

Another interesting finding was that the popular view that dealing with the terminally ill and their relatives is an important source of occupational stress among general practitioners was not confirmed. This aspect of the general practitioner's job may, however, be implicated in a higher consumption of alcohol.

Our findings have several implications. Firstly, Rankin $e t$ al have suggested that general practitioners derive pleasure from exercising their technical skills. ${ }^{20}$ Our study shows these technical skills were not the source of stress among general practitioners, but rather that stress was caused by patients' expectations, job demands, and practice administration. All of these factors entail social and managerial skills, which can be developed by training. Consideration should be given to providing general practitioners with more time management, people management, and work organisation skill development, as this might well help them to overcome some of the daily and chronic stressors of their job. These skills might also help them in trying to minimise the impact of their job on their family life, by providing them with more quality time at home The social skills necessary to cope with patients and managerial skills to administer their practice and deal with the increasing demands of their job have already been widely adopted in many other work settings. ${ }^{2}$ Our findings suggest that there may be substantial benefit in providing a counselling service for general practitioners and other health care workers who find themselves under psychological pressure from their work. We cannot expect general practitioners to be supermen and women; as carers they may find that they need to be cared for as well.

We thank the Nuffield Foundation for funding this study.

1 Mechanic D. General medical practice in England and Wales: its organisation and future. $N$ Engl 7 Med 1968;279:680-9.

2 Porter AMD, Howie JGR, Levinson A. Stress and the general practitioner. In Payne R, Firth-Cozens J, eds. Stress in health professions. Chichester: Wiley, 1987:45-70.

3 Murray RM. Alcoholism amongst male doctors in Scotland. Lancet 1976; ii: 729-33.

4 Bissel L, Jones RW. The alcoholic practitioners: a survey. Am f Psychiatry 1976;133:1142.

5 Allibone A, Oakes D, Shannon HS. The health and health care of doctors. JR Coll Gen Pract 1981;31:328-31.

6 Registrar General. Decennial supplement for England and Wales. London: HMSO, 1978.

7 Rose KD, Roscow I. Physicians who kill themselves. Arch Gen Psychiatry 1973;29:800

8 Morris JN, Heady JA, Barley RG. Coronary heart disease in medical practitioners. Br Med $\mathcal{F} 1952 ;$ i: $503-20$

9 Crown S, Crisp AH. A short clinical diagnostic self rating scale for psychosomatic patients: The Middlesex Hospital questionnaire. Br $\mathcal{f}$ Psychiatr 1966;112:917-25

10 Warr P, Cook J, Wall T. Scales for the measurement of some work attitudes and aspects of psychological well-being. Fournal of Occupational Psychology 1979;52:129-48.

11 Bortner RW. A short rating scale as a potential measure of pattern $\mathrm{A}$ behavior fChronic Dis 1969;22:87-91.

$12 \mathrm{Kasl}$ SV, Cooper CL. Stress and health: issues in research methodology. New York: John Wiley and Sons, 1987.

13 Fry J, Brooks D, McColl I. NHS data book. Lancaster: MTP Press, 1984.

14 Crown S, Crisp AH. Manual of the Crown-Crisp experiential index. Kent Hodder and Stoughton, 1979

15 Makin PJ, Rout U, Cooper CL. Job satisfaction and occupational stress in general practitioners: a pilot study. I R Coll Gen Pract 1988;38:303-6.

16 Everitt B. Cluster analvsis. London: Heinemann Educational Books, 1974.

17 Kerlinger FN, Pedhazer E. Multiple regression in behavioural research. New York: Holt, Rinehart and Winston, 1973.

18 Cartwright A, Anderson R. General practice revisited. London: Tavistock, 1981.

19 Cooper CL, Watts J, Kelly M. Job satisfaction, mental health, and job stressors among general dental practitioners in the UK. Br Dent $f$ 1987:162:77-81.

20 Rankin HJ, Seieys NM, Elliott-Binns CP. Determinants of mood in general practitioners. Br Med f 1987;295:618-20.

21 Cooper CL. Improing interpersonal relations. New Jersey: Prentice Hall, 1982.

(Accepted 9 December 1988)

\section{ONE HUNDRED YEARS AGO}

It will be recollected by our readers that Dr. Holland, of St. Moritz, was one of the English medical men who were fined by the Sanitäts Rath of the Grisons Canton, for practising among their countrymen, but that last summer they were granted the necessary permission by a large majority of the Grosser Rath of the Canton. A local subscription was started to defray Dr. Holland's expenses on this occasion, which, including the fine of 500f. ( $£ 20)$, amounted to about $£ 50$. The sum was readily subscribed by patients and friends, and was presented to him in a purse, in the presence of $\mathrm{Mr}$. Strickland, Mrs. Main, and other subscribers, by Dr. Theodore Williams, who was spending a short Christmas holiday at St. Moritz. Dr. Williams expressed the strong sympathy felt for Dr. Holland at home and abroad in the struggle, which was not only for his own interests, but on behalf of the other English medical men practising in Switzerland, and which, above all, was for the good of English patients, who naturally preferred a skilled countryman of their own to attend them. He congratulated Dr. Holland heartily on his success, and hoped that he might long hold his present position of great utility. Dr. Holland, in a speech of much feeling, accepted the testimonial, and gratefully alluded to the great support and assistance he had received from his friends, including the English medical press. (British Medical Fournal 1889;i:146) 